CDD: 509

\title{
CONSISTENCY FROM THE PERSPECTIVE OF AN EXPERIMENTAL SYSTEMS APPROACH TO THE SCIENCES AND THEIR EPISTEMIC OBJECTS ${ }^{1}$
}

\author{
HANS-JÖRG RHEINBERGER \\ Max Planck Institute for the History of Science \\ Berlin \\ GERMANY \\ rheinbg@mpiwg-berlin.mpg.de
}

\begin{abstract}
It is generally accepted that the development of the modern sciences is rooted in experiment. Yet for a long time, experimentation did not occupy a prominent role, neither in philosophy nor in history of science. With the 'practical turn' in studying the sciences and their history, this has begun to change. This paper is concerned with systems and cultures of experimentation and the consistencies that are generated within such systems and cultures. The first part of the paper exposes the forms of historical and structural coherence that characterize the experimental exploration of epistemic objects. In the second part, a particular experimental culture in the life sciences is briefly described as an example. A survey will be given of what it means and what it takes to analyze biological functions in the test tube.
\end{abstract}

Keywords: Experimental system. Epistemic object. Representation. Epistemic cultures. In vitro experimentation. Model organism.

\section{THE CONCEPT}

The concept of 'experimental system' applies to those experimental arrangements in the laboratories of the world that have become characteristic for the modern empirical sciences at least since the 19th century. Experimental systems can be seen as the smallest integral working units of the experimental sciences of our day and with that,

\footnotetext{
${ }^{1}$ Dedicated - as the contribution of an outsider to his field of work - to Newton da Costa on his 80th anniversary.
}

Manuscrito - Rev. Int. Fil., Campinas, v. 34, n. 1, p. 307-321, jan.-jun. 2011. 
they are the privileged spaces in which the production of knowledge, that is, the generation of new knowledge takes place.

In the research literature of the sciences, the concept of experimental system for the characterization of their specific experimental arrangements has become common parlance around the middle of the 20th century. Compare, e.g., Gale and Folkes (1954, p. 1224) as an example. Often, the notion of 'model system' or simply 'system' is also used synonymously. So, the French molecular biologist François Jacob has emphasized that in his area of work, biology, "any study begins with the choice of a 'system'" (cf. Jacob (1987, p. 234)). In the life sciences, the concept took root especially in connection with the establishment of an in vitro biology and with the coming into use of a series of new 'experimental organisms', or 'model organisms', in particular bacteria and viruses, in the 1930s and the 1940s. Today, the concept is widely used in all of the natural and also the technical sciences. In what follows, the life sciences figure as the reservoir of my examples. The message, however, should be taken as covering the empirical sciences in general. Whether there exist homologous or at least comparable structures in certain areas of logic and mathematics might be an interesting topic for discussion.

A historical comparison may help to set the stage. If philosophers and natural historians spoke of 'systems' toward the end of the 18th century, they meant systems of ideas such as Baron d'Holbach's 'system of nature' (d'Holbach (1770)), or Georges Buffon's 'system of the earth' (Buffon (1749)) or Pierre Louis Moreau de Maupertuis' 'system of the eggs' and 'system of the animalcules' with respect to generation, so eloquently described and criticized in his Vénus physique (Maupertuis (1745)). Also Linné's systema naturae - system of nature - is a categorial one (Linné (1735)). In all these theoretical systems, their protagonists integrated observations and sporadically also experiments as additional arguments and evidences in favor of these systems. These 
observations and experiments, as a rule, were however not the driving forces for the establishment of the systems. At best, they strengthened their credit and plausibility. Two hundred years later, the situation is just the other way round. The guarantee for scientific coherence has been put upside down. Experimental systems - that is, material contrivances - govern the research fields, into which theories and concepts have to be fitted, at least if they want to earn scientific credit and have a real influence on a particular research trajectory.

Despite of its widespread practical use in the everyday language of the scientists, the concept of experimental system has for a long time not been picked up and analyzed with respect to its historiographical and epistemological potential for the description of the modern research process. First hints at such a use we find in the writings of the Polish immunologist and epistemologist Ludwik Fleck. In his book on the Genesis and Development of a Scientific Fact of 1935 he spoke, with respect to his case study of the Wassermann reaction, of a "system of experiments and controls" (Fleck (1935)), but he did not yet make systematic use of the concept. Fleck did however emphasize the fact that the modern research process rests on a stream of experiments and not on singular, isolated experimental acts. His contemporary Karl Popper, as is well known, at the same time opted for the latter view (Popper (1934)). Whether he thus formulated rather an epistemology for the sciences as they prevailed in the 18th century than for the present, we may here leave open. It was only at the beginning of the 1990s and in the context of an ongoing replacement in history of science of a theory-dominated by a practice-dominated perspective on the research process that the concept of experimental system found entrance into the literature of history and philosophy of science (Rheinberger (1992), Rheinberger and Hagner (1993)). From slightly different perspectives, authors have been using expressions such as "manipulable system" (Turnbull and Stokes (1990)), "production system"(Kohler 
(1991)), or "experimental model system" (Amann (1994)). Since then, the concept has gained a wide use, as for instance in Hentschel (1998), Creager (2002).

Now, it needs to be justified if one takes up a concept of the actors, i.e. the scientists themselves, takes it out of the context of the language of the laboratory, and raises it to a more or less central epistemological category for the characterization of the coherence and the dynamics of the units of the empirical research process. The concept of 'system', here as well as in the originary context of the laboratory, is not used with a very strict determination. It stands for a rather lose coherence, but nevertheless for an existing empirical coherence. It appears to be useful to retain this lose determination also in our historiographical and epistemological context. The notion of 'system' then shall only indicate that between the elements of the material culture of the sciences, there exist - if rather flexible - connections that have to be characterized in more detail for every historical context. The concept, that means, is used in a first approximation for the characterization of a certain kind of lose 'coupling', to pick up an expression used by Ludwik Fleck. These couplings exist in a twofold direction. They exist synchronically with respect to the technical and organic elements that enter into an experimental system, and they exist diachronically with respect to the temporal persistence, that is, the existence of an experimental system as a - usually limited - historical research trajectory. Experimental systems are thus entities that persist over time. The advantage of the concept of experimental system lies in its faculty to think and to bind together essential, but nevertheless very different and heterogeneous aspects of the scientific research process - such as instruments and measurement apparatus, preparation arrangements of different kinds, the necessary skills to use them in meaningful ways, the research objects, and not least the spaces in which these moments are brought to interact with each other in productive and creative ar- 
rangements. The notion is thus not one to describe science as a system of theoretical concepts. Rather, the category describes the process of research as a materially mediated process of the generation and the proliferation of knowledge, or to speak with the French anthropologist of science Bruno Latour, of "science in action" (Latour (1987)).

\section{ASPECTS OF THE CONCEPT}

How can experimental systems be characterized with respect to their more general characteristics? Such systems display social and institutional as well as epistemic and technical aspects. The social and institutional aspects shall be only touched here in passing. They point to the fact that experimental systems are always locally situated research connections, thus creating a more or less coherent environment of widely different embeddings for the activities of a single researcher or a whole research group. At the same time they stand for a sufficient demarcation with respect to other, similar neighboring units, that is, they also convey identity and individuality to the work of a single researcher or a particular research group. But there exist also connections that tie together whole groups of experimental systems to historically unique 'research cultures', as I have called these superstructures (Rheinberger (1997)).

\subsection{Epistemic Things and Technical Conditions}

Let us now have a look at the epistemic and technical aspects of experimental systems (see also Rheinberger (1997)). They can be summarized in four points. First, such systems - as I said - constitute the elementary, functional units of empirical research. In them, scientific objects - the objects of epistemic interest - and technical objects that is, the technical conditions of existence of such epistemic entities - are inextricably intertwined. The first entity, the scientific object, is 
that hardly definable something for the sake of which the whole experimental enterprise exists and around which it revolves. Paradoxically speaking, it embodies, in an experimentally manipulable fashion, exactly that which one does not yet know exactly. In a late paper, the noted sociologist of science Robert Merton has spoken in this context of "specified ignorance", and he has pointed to the productive function of this kind of ignorance, or state of not knowing (Merton (1987)). Epistemic things are therefore notoriously underdetermined; they are, so to speak, undefined per definition. In contrast, the technical objects - at least temporarily - are defined in a characteristic manner. They consist of instruments, apparatus and devices that at the same time make possible and constrain the grip on epistemic objects. They require a certain measure of rigidity and precision in order to keep the vagueness of the scientific objects at a sub-critical level. It is therefore often that instruments are set in motion alone in order to test their functional performance - their calibrating and testing probably consumes the greater part of the working time of a scientific experimenter, for the machines are supposed to function as ideally noiseless technical boundary conditions of the experimental work. Within a particular research process, former epistemic things can gain sharp contours and become transformed into technical objects, thus becoming part of the technical conditions of the system. But parts of the technical system also can gain or regain an epistemic status and so be re-transformed into research objects. In this view, the dialectic between the epistemic and the technical is the core of an experimental system; it is its driving force. Experimental systems are therefore to be seen as dynamic, materially conditioned research bodies; they bring scientific objects into existence, and at the same time, determine the boundaries of their conceptual apprehension. With François Jacob once more, it can be said that on their "choice depend the experimenter's freedom to maneuver, the nature of the questions he is free to ask, and even, often, the type 
of answer he can obtain" (Jacob (1987, p. 234)). They thus create 'regional ontologies', as we could add with reference to Evandro Agazzi's opening address to this Symposium.

In this context, a remark on the understanding of scientific instruments is in order. Since the so-called 'practical turn' in history and philosophy of science in the 1980s, instruments have caught particular attention from the part of historians of science. Research instruments, however, must not be hypostasized and taken in isolation. Their scientific meaning derives less from the technical identity conditions that are realized in them - to speak with the French philosopher of science Gaston Bachelard, the "theorems" that are "reified" in them (cf. Bachelard (1949, p. 103)) - but rather from the context of the experimental system in which they are placed as technical objects. Their scientific meaning is thus defined by the epistemic objects with which they are brought to interact and also brought in friction within a particular experimental system. This is a general characteristic of research enabling technologies. And this is also the reason for the particular importance of the interface between instrument and epistemic object for the researcher as well as for the historian of experimental systems (compare Rheinberger (2010, chapter 11)).

\subsection{Reproduction}

Second, experimental systems must be reproduced and must be able to be differentiated permanently in the cycles of their reproduction. Thus we could say, perhaps more neutrally and without necessarily having to understand differentiation in the sense of an increase of complexity, they must be capable of "differing" in the sense of being differentially iterated (Derrida (1972)). Only then do they remain arrangements in which new knowledge is generated, that is, knowledge that lies beyond what can be anticipated and imagined at a particular point in time. Only then do they function, in the words of the Amer- 
ican molecular biologist Mahlon Hoagland, as "generators of surprise" (Hoagland (1990, p. xvii)), or to use an expression of Jacob's, as "machines for making the future" (Jacob (1987, p. 9)). If such a system starts to turn in itself, it is reduced to the simple demonstration of a phenomenon, and so loses its research function. Difference and reproduction are therefore the two inseparable sides of one coin. It is their game and interaction that determines the retardations and the breakthroughs in the course of a research process. In order to remain productive, experimental systems must be arranged and carried on in such a way that the generation of differences becomes the reproductive driving force of the whole machinery. But differential reproduction also lends experimental systems a particular kind of historicity. They can, to speak with philosopher of science Ian Hacking, develop "a life of their own" (Hacking (1983, p. 150)). They are entities that stretch in time: They come into being, they grow, they proliferate, and they can also disappear again.

\subsection{Representation}

Third, experimental systems are those units in which the material semantic carriers of knowledge are produced. They usually begin their life as meaningful traces of some kind that are generated in the system. In their more permanent form, these traces become addressed as 'data'. The horizon of their potential meaning is derived from those spaces of representation in which the material traces and inscriptions are recorded, connected, displaced, enhanced, superposed, marginalized and eventually also replaced. Researchers 'think' with these inscriptions and within the boundaries of such spaces of representation, in the hybrid context thus of the representational machinery at hand, which is given by the totality of the technical conditions of an experimental system. To understand experimental representation, not only 
the activity of the subject has to be taken into account, but also - first and foremost - the means and procedures of representation.

\subsection{Experimental Cultures}

Fourth and lastly, conjunctures and ramifications of experimental systems can lead to whole ensembles of such systems or, as it were, to experimental cultures. Conjunctures as well as ramifications, as a rule, are themselves dependent on the occurrence of unprecedented events within experimental systems. Such experimental events are often triggered by the introduction of new techniques of representation into the system. In the last instance, such experimental ensembles or experimental cultures determine the contours of what Bachelard once called the "cantons" or "cities" of modern knowledge (Bachelard (1949, p. $9)$ ). He has also characterized them as scientific cultures that in their innermost are specified by the "access to an emergence", as he put it (Bachelard (1951, p. 25)). The concept of experimental culture as an articulated ensemble of experimental systems should also allow us to write the history of research fields free from the burden of the traditional history of disciplines. But this is not only a historiographical matter. The more basic argument consists in the observation that the modern experimental sciences derive their dynamics less and less from drawing disciplinary boundaries and from cementing them socially, and more and more from the digressions and transgressions of smaller research units below the level of disciplines, in which knowledge has not yet become labeled and classified, and in which new forms of knowledge can take shape at any time. Through the articulation of such smaller units, novelties generated in one system can quickly spread and create effects at other places. At the same time, however, failures or non-events can remain contained and must not necessarily influence neighboring systems in the negative. One sees thus that there are good 
reasons for the historical fact of a systems structure such as the one brought into being by the modern research process.

\subsection{Experimental Organisms}

A particular feature of experimental systems in the modern life sciences consists in the fact that they are bound to the utilization of 'experimental organisms', or 'model organisms', as they are usually called. From the early modern times until the 19th century, it were above all the differences between the organisms that raised the interest of natural historians who made it their task to mount an exhaustive tableau of the overwhelming diversity of forms of live. Interestingly, under the epistemic regime of the beginning 20th century, the biological differences between organisms became transformed into tools that could be used in order to get access to the most general characteristics of living beings. In this perspective, in other words, the peculiarities of particular organisms are no longer interesting for the sake of themselves. They are only interesting insofar as they allow for a search of generalizable characteristics. One could go even so far as to claim that what came to be called 'General Biology' at the turn from the 19th to the 20th century, in order to get rid of its image as a pure and simple science of order and transform itself into an experimental science, had simply to create the category of model organism. If biology around 1800 meant to pose the question of life as a phenomenon sui generis and to ask for the specific difference between life and non-life, that is, to demarcate life from without, then biology around 1900 meant to tackle the problem of the identification of all those structures and processes that were common to all organisms as such, that is, to define life from within.

Beyond biology, Robert Merton has spoken in this context of what he calls "strategic research materials": According to Merton, it is, I quote, that "empirical material that presents a phenomenon to be ex- 
plained or interpreted in such an advantageous and accessible manner that it renders possible the fruitful investigation of formerly resilient problems and the discovery of new problems for further investigation" (Merton (1987, p. 10-11)). An 'ideal' experimental organism in this sense is, first, an organism that displays a particular interesting phenomenon in a particularly prominent form; but second and even more importantly, an organism that in the context of the establishment of an experimental system can be handled in a particularly efficient fashion. This last point is decisive: In order to function as an experimental organism, the living being must be embedded in an experimental system in which it can display its dynamic and fulfill its role as a model. But model organisms, as a rule, are always also organisms modified for particular research purposes. In that sense, they are research tools; they are not epistemic objects, but something like organic instruments that, in order to allow for the investigation of epistemic objects, have to be purified, trimmed, and standardized.

\subsection{In vitro Systems}

A second peculiarity of experimental systems in the life sciences is given by the differentiation between in vitro and in vivo systems. This distinction developed at the beginning of the 20th century, after it had been shown that not only secreted enzymes - such as intestinal enzymes - can function out of the body, but also intracellular enzymes, at least under appropriate buffer conditions. Of course, working with dead bodies and the production of preparations has a far longer history. But the in vitro systems of the first half of the 20th century claimed to create artificial environments in which processes normally occurring in intact cells could be reproduced extra cellulam, thus creating new possibilities for analytical investigation. With that, they marked the transition from the experiment on the living body to work with isolated tissues and cells, to a sub-cellular, and finally to a molecular knowledge 
regime. In vitro systems are reduced systems. They expose certain elements of a complex metabolic network and eliminate or purify away others. They offer completely new interfaces between the biological object of investigation and a whole arsenal of research instruments. But since they are prone to produce artifacts, they need to be permanently controlled by binding their results back - in one way or another - to the in vivo situation. A good part of the history of molecular biology in the 20th century has inscribed itself into this peculiar game of corroboration and rectification.

\section{CONCLUSION}

What good is the concept of experimental system for a historical epistemology of the sciences? The comparative investigation of the complex structures that this concept covers should help us to understand how new knowledge - that is knowledge that in essence cannot be anticipated - is generated in the process of research. Structurally, the new is always the result of a spatial and temporal singularity. There are good reasons to assume that the generation of new knowledge in the empirical sciences of the 19th and the 20th century is fundamentally bound to those structures that I have characterized as experimental systems. They are exactly those material contrivances with which in the context of knowledge acquisition researchers are able to generate such singularities. To formulate it paradoxically: They allow for the generation of knowledge effects in a regular and regulated manner, and yet transcend our limited capability of anticipation. In exactly this sense we could - once more with Bachelard - say that the "scientific real" (le reel scientifique) is not the final point of reference for the scientific spirit (cf. Bachelard (1934, p. 6), here misleadingly translated as "scientific reality"); rather, the specific reality of the scientific real consists in pointing beyond itself, in creating a space for unprece- 
dented events. In exactly this sense experimental systems are, if you will, more and differently 'real' than our everyday reality. The reality of an epistemic thing to be explored in an experimental system lies in its resistance, its resilience, its capacity to form an obstacle and to defy our foresight. As the chemist and philosopher of science Michael Polanyi once remarked: "To trust that a thing we know is real is, in this sense, to feel that it has the independence and power for manifesting itself in yet unthought of ways in the future" (Polanyi in Grene (1984, p. 219)).

\section{REFERENCES}

AMANN, K. "Menschen, Mäuse und Fliegen. Eine wissenssoziologische Analyse der Transformation von Organismen in epistemische Objekte". In Michael Hagner, Hans-Jörg Rheinberger, and Bettina Wahrig-Schmidt (eds.), Objekte, Differenzen und Konjunkturen. Experimentalsysteme im historischen Kontext. Akademie Verlag, Berlin, p. 259-289, 1994.

BACHELARD, G. L'activité raionaliste de la physique contemporaine. Presses Unversitaires de France, Paris 1951.

. Le rationalisme appliqué. Presses Universitaires de France, Paris 1949.

. The New Scientific Spirit, 1934. Beacon Press, Boston 1984.

BUFFON, G. Histoire naturelle générale et particulière. Tome I, Imprimerie du Roi, Paris, 1749.

CREAGER, A. N. H. The Life of a Virus: Tobacco Mosaic Virus as an Experimental Model, 1930-1965. University of Chicago Press, Chicago, 2002.

Manuscrito - Rev. Int. Fil., Campinas, v. 34, n. 1, p. 307-321, jan.-jun. 2011. 
DERRIDA, J. "Différance", 1972. In: J. Derrida, Margins of Philosophy. Harvester, Brighton, 1982.

FLECK, L. Genesis and Development of a Scientific Fact, 1935. Chicago University Press, Chicago, 1979.

GALE, E. F. and JOAN P. F. "Effect off nucleic acids on protein synthesis and amino-acid incorporation in disrupted staphylococcal cells". Nature, 173, 1223-1227, 1954.

GRENE, M. The Knower and the Known. Center for Advanced Research in Phenomenology \& University Press of America, Washington, 1984.

HACKING, I. Representing and Intervening. Introductory Topics in the Philosophy of Natural Science. Cambridge University Press, Cambridge, 1983.

HENTSCHEL, K. Zum Zusammenspiel von Instrument, Experiment und Theorie. Rotverschiebung im Sonnenspektrum und verwandt spektrale Verschiebungseffekte von 1880 bis 1960. Verlag Dr. Kovac, Hamburg, 1998.

HOAGLAND, M. B. Toward the Habit of Truth. A Life in Science. W. W. Norton \& Company, New York and London, 1990.

HOLBACH, P. System of Nature, or Laws of the Moral and Physical World, 1770. Burt Franklin, New York, 1970.

JACOB, F. The Statue Within: An Autobiography. Basic Books, New York, 1988.

KOHLER, R. "Systems of production: Drosophila, Neurospora, and biochemical genetics". Historical Studies in the Physical and Biological Sciences, 22, p. 87-130, 1991.

. Lords of the Fly. The University of Chicago Press, Chicago, 1994. 
LATOUR, B. Science in Action. How to Follow Scientists and Engineers through Society. Harvard University Press, Cambridge, 1987.

LINNÉ, C. Systema naturae. Lugdunum Batavorum, 1. Edition, 1735.

MAUPERTUIS, P-L. M. Vénus physique. Paris, 1745.

MERTON, R. K. "Three fragments from a sociologist's notebooks: Establishing the phenomenon, specified ignorance, and strategic research materials". Annual Review of Sociology 13, p. 1-28, 1987.

POPPER, K. The Logic of Scientific Discovery, 1934. Hutchinson, London, 1968.

RHEINBERGER, H.-J. Experiment, Differenz, Schrift. Zur Geschichte epistemischer Ddinge. Basiliskenpresse, Marburg, 1992.

. Toward a History of Epistemic Things. Synthesizing Proteins in the Test Tube. Stanford University Press, Stanford, 1997.

. Epistemologie des Konkreten. Studien zur Geschichte der modernen Biologie. Suhrkamp, Frankfurt am Main, 2006.

. An Epistemology of the Concrete. Twentieth Century Histories of Life. Duke, Durham and London, 2010.

RHEINBERGER, H.-J. and HAGNER, M. (eds.). Die Experimentalisierung des Lebens. Experimentalsysteme in den biologischen Wissenschaften 1850/1950. Akademie Verlag, Berlin, 1993.

TURNBULL, D. and STOKES, T. "Manipulable systems and laboratory strategies in a biomedical institute". In Homer E. Le Grand (Hrsg.), Experimental Inquiries. Kluwer, Dordreccht, p. 167192, 1990. 